\title{
(Research Article) \\ Study and Investigation of the Nature of Metallic Destruction in Crude Oils
}

\author{
Suresh Aluvihara $^{1 *}$, Jagath K. Premachandra ${ }^{2}$ \\ ${ }^{1 *}$ Department of Chemical and Process Engineering, University of Peradeniya, Peradeniya, Sri Lanka \\ ${ }^{2}$ Department of Chemical and Process Engineering, University of Moratuwa, Katubedda, Sri Lanka
}

\begin{abstract}
Metallic destruction is a plentiful utterance regarding the crude refining industry while it is causing undesirable coercion on the durability. The investigations of the impact of dominant corrosive properties of two different types of crude oils on the corrosion rates of seven different types of ferrous metals, qualitative analysis of the corrosion, and analysis of the decay of the metals into crude oils were the pivotal objectives of this study. The significant corrosive compounds of both crude oils were tested by standard methods and instruments. A prepared set of similar sized metal coupons were immersed separately in both crude oils to determine their corrosion rates in order of after certain immersion periods by weight loss method while observing the corroded metal surfaces through the 400X lens of an optical microscope. The decayed metal concentrations into crude oils were tested. The deductions of the initial hardness of metal coupons were tested. There were found lower corrosion rates from stainless steels in both crude oils, higher corrosive tendency from the salts in crude oils, formations of the $\mathrm{FeS}, \mathrm{Fe}_{2} \mathrm{O}_{3}$, corrosion cracks and cavities, decay of ferrous and copper into crude oils regarding some metals and the reductions of the initial hardness of each metal coupon after corrosion.
\end{abstract}

Keywords: Ferrous metals, Crude oils, Corrosive properties, Weight loss, Destruction, Hardness

\section{Introduction}

Metallic corrosion is a major stuff of the destruction of such metals due to the chemical or electrochemical reactions between the metal and the surrounded environment [1]-[5]. Usually the corrosion is defined as the chemical oxidizing process regarding the ferrous metals. In this process the metal need to be elicited to either an oxidizing agent that stronger than the $\mathrm{Fe}^{2+}$ or any environment that consisted with both oxygen and water. Also formation of the metallic sulfides, oxides or hydroxides on the metal surface itself as the results of above chemical oxidizing process are the characteristics of the corrosion [1][3][4][5]. According to the corrosion type of occurrence and the features of corrosion compounds the corrosion can be categorized into some of sub categories such as general corrosion, pitting corrosion, galvanic corrosion and thermal corrosion [1]- [18]. Also such corrosion mechanisms are distinguished based on their features such as the color, surface changes and the chemical compositions of such corrosion compounds. The corrosive compounds are found from various materials such as both organic and inorganic solvents [1]-[10]. According to the chemical compositions of crude oils usually found some trace compounds foremost of corrosive compounds apart from the

*Corresponding Author: e-mail: sureshaluvihare@gmail.com, ISSN 2320-7590

(C) 2019 Darshan Institute of Engg. \& Tech., All rights reserved majority of hydrocarbons.

Regarding recent and previous studies on the corrosive compounds and their impact on the metallic corrosion mainly there were found some significant progress from salts, organic acids and a series of the forms of sulfur at different specific conditions such as the different temperatures [1][21]. In the industry of crude oil refining it seems different kinds of applications in ferrous metals that able to interact with crude oils under various conditions of crude oils as given in the below [2] [6] [8].

- Crude distillation column- High temperature

- $\quad$ Preheating units- High temperature

- Desalting units- High salt content

In the contemporary research there were expected to speculate the effect of the corrosive properties of two different types of crude oils on the corrosion rates of seven different types of selected ferrous metals which are applicable in the industry of crude oil refining, to analyze the corrosion compounds qualitatively, to analyze the decayed metal concentrations into crude oils quantitatively and to investigate the deductions of the initial hardness of metals due to the corrosion. 


\section{Materials and Methods}

\subsection{Materials:}

2.1.1 Ferrous Metals: The selected sample of metals was consisted with three different types of stainless steels, three different types of carbon steels and Monel metal because of the usages in the industry of crude oil refining in significantly. Some specific usages of selected ferrous metals have been shortlisted in the below.

- Carbon Steel (High)- Storage tanks

- Carbon Steel (Medium)- Storage tanks and transportation tubes

- Carbon Steel (Mild Steel)- Storage tanks and pipes

- 410-MN: 1.8 420-MN: 2.8 (Stainless Steel)- Crude distillation columns

- 410-MN: 1.7 420-MN: 1.7 (Stainless Steel)- Crude distillation columns

- 321-MN: 1.4 304-MN: 1.9 (Stainless Steel)- Crude distillation columns and pre heaters

- Monel 400- Pre heaters

2.1.2 Crude oils: The selected crude oils are typically using crude oils in most of crude oil refining plants recently namely as Murban and Das Blend and also those oils are slightly and numerously different in each other because of the dependability of the compositions of crude oils on their occurrences. According to the natural occurrence of crude oils that those crude oils may consist predominantly with large number of hydrocarbons, volatile organic compounds and some corrosive compounds as well such as sulfur, organic acids and salts. When considering both selected crude oils the Das Blend is known as a "sour" crude oil because of the higher sulfur content of that crude oil since Murban is having prosaic properties [6] -[15]. The important corrosive properties of both Murban and Das Blend crude oils were tested by standard test methods and instruments which are important in the current investigation of the nature of the metallic corrosion in crude oils.

\subsection{Methodology}

2.2.1 Investigations of the corrosive properties of crude oils: A descriptive summary about the important information regarding such experiments to investigate the corrosive properties of crude oils have been given in the Table 1.

Table 1. Test methodologies of corrosive properties of crude oils

\begin{tabular}{|c|c|c|}
\hline Property & Method & Readings \\
\hline Sulfur content & Directly used crude oil & Direct \\
\hline
\end{tabular}

\begin{tabular}{|c|c|c|}
\hline & $\begin{array}{c}\text { samples to the XRF } \\
\text { analyzer. }\end{array}$ & reading \\
\hline Acidity & $\begin{array}{c}\text { Each sample was dissolved } \\
\text { in a mixture of toluene and } \\
\text { isopropyl and titrated with } \\
\text { potassium hydroxide. }\end{array}$ & $\begin{array}{c}\text { End } \\
\text { point }\end{array}$ \\
\hline $\begin{array}{c}\text { Mercaptans } \\
\text { content }\end{array}$ & $\begin{array}{c}\text { Each sample was dissolved } \\
\text { in sodium acetate and } \\
\text { titrated with silver nitrate. }\end{array}$ & $\begin{array}{c}\text { End } \\
\text { point }\end{array}$ \\
\hline Salt content & $\begin{array}{c}\text { Each sample was dissolved } \\
\text { in organic solvent and } \\
\text { exposed to the cell of } \\
\text { analyzer. }\end{array}$ & $\begin{array}{c}\text { Direct } \\
\text { reading }\end{array}$ \\
\hline \multicolumn{2}{|c}{} \\
\hline
\end{tabular}

2.2.2 Chemical compositions of ferrous metals: The chemical compositions of selected types of metals were detected by the $\mathrm{XRF}$ detector. The XRF detector is an instrument which is working under the principles of X-rays and it allows to be measured the composed metallic percentages and some non metallic element percentages excluding carbon [1] - [10].

2.2.3 Determination of the corrosion rates of metals and the microscopic analysis: Batches of similar sized metal coupons were prepared in each type of metal in equal dimensions as a precaution of the further calculations and six metal coupons were prepared in each metals type as altogether forty two metal coupons from seven different types of metals. The dimensions and initial weight of the well cleaned metal coupons were measured by in order of micrometers and electronic balance. The prepared metal coupons have been shown in the Figure. 1.

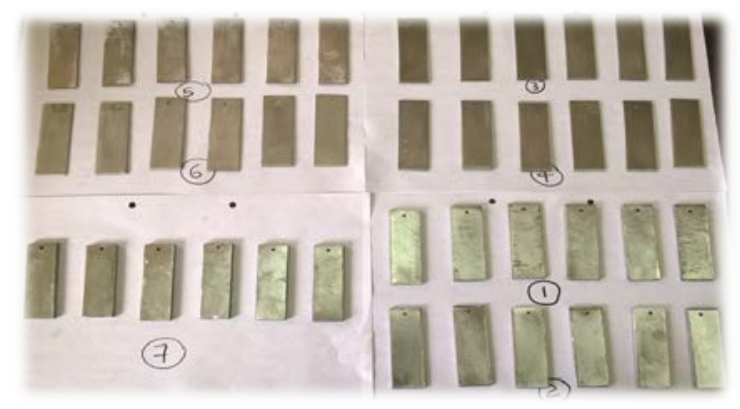

Figure.1. Prepared metal coupons

The prepared metal coupons were separately immersed in both Murban and Das Blend crude oils as three metal coupons of some metal type in a container of Murban crude oil and other three metal coupons of such metal type in a 
crude oil container of Das Blend crude oils homogeneously. The same procedure was repeated for another metals and altogether prepared seven Murban crude oil containers and seven Das Blend crude oil containers as shown in the Fig. 2(a) and Fig 2(b).

(a)

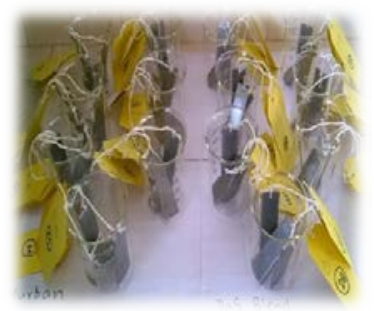

Figure.2. (a) Metal coupons and (b) the immersed metal coupons

After 15 days from the immersion of the metal coupons in crude oils the first batch of metal coupons alias one metal coupon was taken out of three from each crude oil container and the corroded surfaces were observed by the $400 \mathrm{X}$ lens of the laboratory optical microscope and the corrosion compounds on such metal surfaces were identified based on the visible features of such corrosion compounds. Then the corroded metallic surfaces were cleaned by the sand papers and isooctane while observing through the $400 \mathrm{X}$ lens of the previous optical microscope until free of corrode on the metal surface and the final weight of each metal coupon was measured by the electronic balance also the corrosion/ destruction rate of each metal coupon was determined by the relative weight loss method [10] [18] [20] [21]. The mathematical expression and the important terms of that method have been explained in the Eq. 1.

$$
\mathrm{CR}=\mathrm{W} * \mathrm{k} /(\mathrm{D} * \mathrm{~A} * \mathrm{t})
$$

Where;

$\mathrm{W}=$ weight loss in grams

$\mathrm{k}=$ constant $(22,300)$

$\mathrm{D}=$ metal density in $\mathrm{g} / \mathrm{cm}^{3}$

$\mathrm{A}=$ area of metal piece $\left(\right.$ inch $\left.^{2}\right)$

$\mathrm{t}=$ time (days)

$\mathrm{CR}=$ Corrosion rate of metal piece

2.2.4 Decay of metals into crude oils: Subsequently the same procedure was repeated for another two remaining sets of samples and the metal coupons were taken out from the crude oil container in order of after 30 and 45 days from the immersion to determine the corrosion/ destruction rate of such metal coupons same as the previous set of metal coupons. Finally the average corrosion rates of each metal type were calculated by the obtain results for the corrosion rates after 15, 30 and 45 days with respect to both Murban and Das Blend crude oils separately.
Due to the requirement of the further clarification for the observed invisible weight loss during the determination of the corrosion rates of some metal coupons there were analyzed the decayed ferrous concentrations from stainless steels and carbon steels into crude oils and also the decayed copper concentration from Monel metal into the crude oils by the atomic absorption spectroscopy (AAS). According to the methodology of sample preparation $1 \mathrm{ml}$ of each crude oil sample was diluted with $9 \mathrm{ml}$ of 2-proponol and filtered before sending to the suction of the instrument.

2.2.5 Variations of the hardness of metals: As a confirmation stage of the formation of the corrosion the variations of the initial hardness of metal coupons after the formation of the corrosion were tested by the Vicker's hardness tester. According to the working principle of the Vicker's hardness tester it allows to measure the hardness of one point on the metal surface at once. Therefore, there were tested at the hardness of at least three points on the metal surface for one measurement and the average values were interpreted as the results. In the analysis of the variations of the hardness the initial hardness and final hardness or the hardness after formation of the corrosion on the metal surface were reckoned regarding each metal coupon [1] [4] [5] [20] [24].

\section{Results and Discussion}

3.1 Chemical compositions of ferrous metals: According to the obtained results for the analysis of the chemical compositions of selected ferrous metals the elemental compositions have been summarized $n$ the Table 2 .

The chemical compositions of the metals were slightly or materially different especially from the amounts of ferrous and other trace metal. As the fundamental observations of this experiment there were found relatively higher ferrous concentrations in carbon steels, intermediate ferrous concentrations in stainless steels and trace amount of ferrous in the Monel metal. When considering the chemical compositions of stainless steels that there were observed the doping of some amounts of chromium and nickel [1] [3] [5] [23] [24]. Stainless steels are the modifications of the ferrous metals aiming the enhancements of the properties of such metals as given in the below.

- Improvement of the hardness

- Enhancements of the strength such as the tensile strength

- Reduce the corrosion rates/ enhance the corrosive protection strength

- Enhance some other mechanical properties rather than the pure metal. 
In the case of the enhancements of the corrosive protection strength of stainless steels the initial ferrous metals need to be doped with some particular percentages of both nickel and chromium according to the theoretical explanation about the self corrosive protection film of the stainless steels against the corrosive environment. The typical value of the chromium is at least $12 \%$ with sufficient amount of nickel to form the self corrosive protection film to prevent the corrosion in rush [1] [3] [4] [5].

Table 2. Chemical compositions of selected ferrous metals

\begin{tabular}{|c|c|c|c|c|}
\hline Metal & $\mathrm{Fe}(\%)$ & $\mathrm{Ni}(\%)$ & $\mathrm{Cr}(\%)$ & $\mathrm{Cu}(\%)$ \\
\hline $\begin{array}{c}\text { (1)Carbon Steel } \\
\text { (High) }\end{array}$ & 98.60 & 0.17 & 0.14 & 0.37 \\
\hline $\begin{array}{c}\text { (2)Carbon Steel } \\
\text { (Medium) }\end{array}$ & 99.36 & - & - & - \\
\hline $\begin{array}{c}\text { (3) Carbon Steel } \\
\text { (Mild Steel) }\end{array}$ & 99.46 & - & $<0.07$ & - \\
\hline $\begin{array}{c}\text { (4) 410-MN: } 1.8 \\
\text { 420-MN: 2.8 } \\
\text { (Stainless Steel) }\end{array}$ & 88.25 & 0.18 & 10.92 & 0.10 \\
\hline $\begin{array}{c}\text { (5) 410-MN: } 1.7 \\
\text { 420-MN: } 1.7 \\
\text { (Stainless Steel) }\end{array}$ & 87.44 & - & 11.99 & - \\
\hline $\begin{array}{c}\text { (6) 321-MN:1.4 } \\
\text { 304-MN:1.9 } \\
\text { (Stainless Steel) }\end{array}$ & 72.47 & 8.65 & 17.14 & - \\
\hline \begin{tabular}{c} 
(7)Monel 400 \\
\hline
\end{tabular} & 1.40 & 64.36 & $<0.04$ & 33.29 \\
\hline
\end{tabular}

3.2 Corrosive properties of crude oils: According to the analysis of the corrosive properties in both Murban and Das Blend the obtained results have been exhibited in the Table 3.

Table 3. Corrosive properties of both Murban and Das Blend crude oils

\begin{tabular}{|c|c|c|}
\hline Property & Murban & Das Blend \\
\hline Sulfur content (Wt. \%) & 0.758 & 1.135 \\
\hline Salt content (ptb) & 4.4 & 3.6 \\
\hline Acidity (mg KOH/g) & 0.01 & 0.02 \\
\hline $\begin{array}{c}\text { Mercaptans content } \\
\text { (ppm) }\end{array}$ & 25 & 56 \\
\hline
\end{tabular}

The obtained results for the salt contents regarding both Murban and Das Blend crude oils Murban showed higher amount of salts when comparing with Das Blend crude oil. Usually the term of "salt content" indicates the total of the compositions of $\mathrm{NaCl}, \mathrm{MgCl}_{2}$ and $\mathrm{CaCl}_{2}$ in a crude oil [7]. These salts are composed with crude oils since the occurrence of such crude oils. When the system is approaching towards some higher temperatures while heating in various processes of crude oil refining those salts may have a propensity of breaking into $\mathrm{HCl}$ molecules although such $\mathrm{HCl}$ molecules are behaved as neutral compounds at that stage. The chemical reaction which is related with above phenomenon has been given in the Eq. 2 .

$$
\mathrm{CaCl} 2+\mathrm{H} 2 \mathrm{O} \rightarrow \mathrm{CaO}+2 \mathrm{HCl}
$$

Although when the system is approaching to lower temperatures such $\mathrm{HCl}$ molecules tend to react with the moistures and water presence in crude oils and produce hydrochloric acids and hydrogen sulfide which are known as the highly corrosive compounds [2][4][7]. According to the remaining phases of both compounds easily it can be concluded the effect of hydrochloric acids is much stronger on the metallic corrosion based on a few things as given in the below.

- Hydrogen sulfide is a gas and suddenly it will be escaped to the gas phase of the container

- The research was conducted in an open system

- Hydrochloric acid is in the liquid phase and allow to interact with metal coupons vastly

The chemical resections of the mechanism of corrosion and reproducing the $\mathrm{HCl}$ have been given in the Eq. 3 and Eq. 4.

$$
\begin{aligned}
& \mathrm{HCl}+\mathrm{Fe} \rightarrow \mathrm{FeCl} 2+\mathrm{H} 2 \\
& \mathrm{FeCl} 2+\mathrm{H} 2 \mathrm{~S} \rightarrow \mathrm{FeS}+2 \mathrm{HCl}
\end{aligned}
$$

The obtained results for the acid contents of both Murban and Das Blend crude oils the Das Blend crude oil was composed with relatively higher amount of organic acids than the Murban crude oil. The organic acids are also highly corrosive compounds presence in crude oils since the occurrences of such crude oils. In other words these organic acids are known with a term of "naphthenic acids" which are having a chemical formula of "RCOOH" [2] [4] [9] [12] [15]. The important chemical reactions of the interaction between ferrous metals and such organic acids have been given in the Eq. 5, Eq. 6 and Eq. 7.

$$
\begin{aligned}
& \mathrm{Fe}+2 \mathrm{RCOOH} \rightarrow \mathrm{Fe}(\mathrm{RCOO}) 2+\mathrm{H} 2 \\
& \mathrm{FeS}+2 \mathrm{RCOOH} \rightarrow \mathrm{Fe}(\mathrm{RCOO}) 2+\mathrm{H} 2 \mathrm{~S} \\
& \mathrm{Fe}(\mathrm{COOR}) 2+\mathrm{H} 2 \mathrm{~S} \rightarrow \mathrm{FeS}+2 \mathrm{RCOOH}
\end{aligned}
$$

Under the above mechanism the major corrosive agent is hydrogen sulfide although cannot be expected a proper contribution of the metal coupons in the current experiment because of the escaping ability of such hydrogen sulfides into the gas phase instead of remaining in the liquid phase to interact with such metals and also the interaction between such hydrogen sulfide and metals might be limited for quite 
short time even less than a second. Under this process the previously formed $\mathrm{FeS}$ also reacts with the organic acids in some recent moments. Therefore, it can be emphasized to modification activity of organic acids of the formation of corrosion by linking with another possible corrosion mechanism forever.

According to the obtained results for both sulfur contents and Mercaptans contents of both Murban and Das Blend crude oils there were found that the Das Blend crude oil was composed some higher amount of elemental sulfur and Mercaptans than the Murban crude oil. Since the occurrences of crude oils it may be possible to composed with some significant amount of sulfur because of the formerly abundance of sulfur in the earth crust and the mantle of the earth where these crude oils are occurring. This sulfur can be categorized into some specific groups of compounds by considering the functional groups and phases of them such as elemental sulfur, Mercaptans, hydrogen sulfide, thiophenes and sulfoxides also most of them are known as the corrosive compounds [2][4][13]. Based on the corrosive ability of such compounds there was established a separate unit to remove such sulfur and other compounds from the raw crude oils and some end products as well in every crude oil refining plant in the world. The corrosion process and the required conditions may be varied with the type of sulfur compound especially the reactivity of the functional group. Mercaptans are the active sulfur compound which is having a general chemical formula of "RSH" [2] [4] [8]. Basically there were considered two of well defined processes which are related with Mercaptans and elemental sulfur as given in the below [13] [14].

- Related with elemental sulfur the process is called as the "localized corrosion" usually occurring at about $80^{\circ} \mathrm{C}$ in proper manner.

- Related with the Mercaptans the process is called as the "sulfidation" usually occurring at about $230^{\circ} \mathrm{C}$ in proper manner.

- Most of active sulfur compounds involves in the metallic corrosion undergoing both "sulfidation" and "localized corrosion"

The general chemical reactions related with above mentioned corrosion processes have been given in the Eq. 8 and Eq. 9.

$$
\begin{array}{r}
\mathrm{S} 8(\mathrm{~s})+8 \mathrm{H} 2 \mathrm{O}(\mathrm{l}) \rightarrow 6 \mathrm{H} 2 \mathrm{~S}(\mathrm{aq})+2 \mathrm{H} 2 \mathrm{SO} 4 \\
8 \mathrm{Fe}+\mathrm{S} 8 \rightarrow 8 \mathrm{FeS}
\end{array}
$$

Regarding these processes the corrosive agents were the sulfuric acids, hydrogen sulfides and direct formation of FeS. In the analysis of the strength of such compounds the effect of hydrogen sulfide might be less because of the gas phase and less retention time in liquid phase. There might have affected sulfuric acids on the metallic corrosion because of the liquid phase although it is difficult to expect some proper progress because of the requirements of above temperature conditions. In addition that it is possible to assume that there might be some impact from other compounds which were nit mentioned in the existing research and relevant scope.

3.3 Corrosion rates of metals: According to the obtained results for the corrosion rates of metal coupons with respect to both Murban and Das Blend crude oils in order of after 15, 30 and 45 days have been given in the Table 4 and Table 5 .

The concluded graphical representations for the above results as average corrosion rates of each metal type with respect to both Murban and Das Blend crude oils have been shown in the Figure. 3.

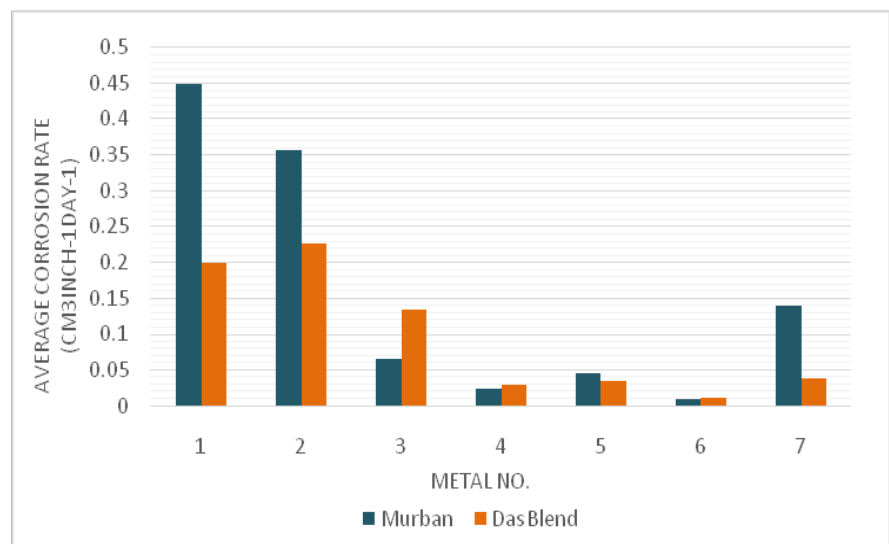

Figure.3. Average corrosion rates of metal types in both Murban and Das Blend crude oils

By referring the obtained results for the corrosion rates of metal coupons there were observed the asymmetric distribution of the values for the corrosion rates of metal coupons after recent time period of exposed to the crude oils and for the convenience of the discussion the average values were calculated and interpreted. By considering such concluded results there can be found the relatively higher corrosion rates from carbon steels, intermediate corrosion rates from the Monel metal and the lower corrosion rates were observed stainless steels. When comparing the corrosion rates of stainless steels the least corrosion rate was found from 321-MN: 1.4 304-MN: 1.9 (Stainless Steel) with respect to both Murban and Das Blend crude oils. According to the chemical composition of 321-MN: 1.4 304-MN: 1.9 (Stainless Steel) it was composed with $\sim 18 \%$ of chromium and $\sim 8.7 \%$ of nickel. Regarding the theoretical explanation of the self corrosive protection layer of the stainless steels the minimum requirement for that corrosive protection layer is $\sim 12 \%$ chromium with sufficient amount of nickel [1][3][4][5][20][21][23].

Table 4. Corrosion rates of metal coupons in Murban crude oil

\begin{tabular}{|c|c|c|c|c|}
\hline \multirow{2}{*}{ Metal } & $\begin{array}{l}\text { Corrosion } \\
\text { Rate after }\end{array}$ & $\begin{array}{l}\text { Corrosion } \\
\text { Rate after }\end{array}$ & $\begin{array}{c}\text { Corrosion } \\
\text { Rate after }\end{array}$ & $\begin{array}{c}\text { Average } \\
\text { Corrosion }\end{array}$ \\
\hline
\end{tabular}




\begin{tabular}{|c|c|c|c|c|}
\hline & $\begin{array}{c}15 \text { Days } \\
\left(\mathrm{cm}^{3}\right. \\
\text { inch }^{-1} \\
\left.\text { day }^{-1}\right) \\
\end{array}$ & $\begin{array}{c}30 \text { Days } \\
\left(\mathrm{cm}^{3}\right. \\
\text { inch }^{-1} \\
\left.\text { day }^{-1}\right) \\
\end{array}$ & $\begin{array}{c}45 \text { Days } \\
\left(\mathrm{cm}^{3}\right. \\
\text { inch }^{-1} \\
\left.\text { day }^{-1}\right) \\
\end{array}$ & $\begin{array}{c}\text { Rate } \\
\left(\mathrm{cm}^{3} \text { inch }^{-}\right. \\
\left.{ }^{1} \text { day }^{-1}\right)\end{array}$ \\
\hline $\begin{array}{c}\text { (1)Carbon } \\
\text { Steel } \\
\text { (High) }\end{array}$ & 0.811971 & 0.466425 & 0.068794 & 0.4490632 \\
\hline $\begin{array}{c}\text { (2)Carbon } \\
\text { Steel } \\
\text { (Medium) }\end{array}$ & 0.817791 & 0.180339 & 0.073358 & 0.3571623 \\
\hline $\begin{array}{c}\text { (3) } \\
\text { Carbon } \\
\text { Steel } \\
\text { (Mild } \\
\text { Steel) }\end{array}$ & 0.10973 & 0.048244 & 0.038592 & 0.0655217 \\
\hline $\begin{array}{c}\text { (4) 410- } \\
\text { MN: } 1.8 \\
\text { 420-MN: } \\
2.8 \\
\text { (Stainless } \\
\text { Steel) }\end{array}$ & 0.041784 & 0.016075 & 0.011801 & 0.02322 \\
\hline $\begin{array}{c}\text { (5) 410- } \\
\text { MN: } 1.7 \\
\text { 420-MN: } \\
1.7 \\
\text { (Stainless } \\
\text { Steel) }\end{array}$ & 0.11626 & 0.011968 & 0.007574 & 0.0452676 \\
\hline $\begin{array}{c}\text { (6) 321- } \\
\text { MN:1.4 } \\
304- \\
\text { MN:1.9 } \\
\text { (Stainless } \\
\text { Steel) } \\
\end{array}$ & 0.016612 & 0.007453 & 0.005599 & 0.009888 \\
\hline $\begin{array}{c}\text { (7)Monel } \\
400\end{array}$ & 0.356263 & 0.034877 & 0.026729 & 0.13929 \\
\hline
\end{tabular}

Also comparing the corrosion rates and chemical compositions of other two types of stainless steels there can be observed relatively higher corrosion rates from 410-MN: 1.7 420-MN: 1.7 (Stainless Steel) in both crude oils since the chemical composition of $\sim 12 \%$ of chromium and lack of nickel. The other type of stainless steel had an intermediate corrosion rates among other stainless steels in both crude oils since the chemical composition is $\sim 11 \%$ of chromium and $\sim 0.2 \%$ of nickel.

Table 5. Corrosion rates of metal coupons in Das Blend crude oil

\begin{tabular}{|c|c|c|c|c|}
\hline \multirow{5}{*}{ Metal } & Corrosion & Corrosion & Corrosion & Average \\
& Rate after & Rate after & Rate after & Corrosion \\
& 15 Days & 30 Days & 45 Days & Rate \\
& $\left(\mathrm{cm}^{3}\right.$ & $\left(\mathrm{cm}^{3}\right.$ & $\left(\mathrm{cm}^{3}\right.$ & $\left(\mathrm{cm}^{3}\right.$ inch $^{-}$ \\
& inch $^{-1}$ & inch $^{-1}$ & inch $^{-1}$ & 1 day $\left.^{-1}\right)$ \\
\hline day $\left.^{-1}\right)$ & day $\left.^{-1}\right)$ & day $\left.^{-1}\right)$ & ${ }^{2}$ \\
\hline
\end{tabular}

\begin{tabular}{|c|c|c|c|c|}
\hline $\begin{array}{c}\text { (1)Carbon } \\
\text { Steel } \\
\text { (High) }\end{array}$ & 0.350249 & 0.224901 & 0.024738 & 0.1999627 \\
\hline $\begin{array}{c}\text { (2)Carbon } \\
\text { Steel } \\
\text { (Medium) }\end{array}$ & 0.481055 & 0.140654 & 0.05911 & 0.2269396 \\
\hline $\begin{array}{c}\text { (3) } \\
\text { Carbon } \\
\text { Steel } \\
\text { (Mild } \\
\text { Steel) }\end{array}$ & 0.162883 & 0.141093 & 0.100635 & 0.1348702 \\
\hline $\begin{array}{c}\text { (4) 410- } \\
\text { MN: } 1.8 \\
\text { 420-MN: } \\
2.8 \\
\text { (Stainless } \\
\text { Steel) }\end{array}$ & 0.044146 & 0.034035 & 0.006149 & 0.0281102 \\
\hline $\begin{array}{c}\text { (5) 410- } \\
\text { MN: } 1.7 \\
\text { 420-MN: } \\
1.7 \\
\text { (Stainless } \\
\text { Steel) }\end{array}$ & 0.053701 & 0.034841 & 0.016363 & 0.0349681 \\
\hline $\begin{array}{c}\text { (6) 321- } \\
\text { MN:1.4 } \\
304- \\
\text { MN:1.9 } \\
\text { (Stainless } \\
\text { Steel) }\end{array}$ & 0.022894 & 0.006503 & 0.002825 & 0.0107404 \\
\hline $\begin{array}{c}\text { (7)Monel } \\
400\end{array}$ & 0.061554 & 0.037655 & 0.016067 & 0.0384254 \\
\hline
\end{tabular}

By considering such important results of the current results and the literature reviews there can be reached to some important approaches about the efficiency of self corrosive protection film against the corrosive environment as given in the below.

- The optimal performances are given at least $12 \%$ of chromium with sufficient amount of nickel

- Necessity of both chromium and nickel in the recommended amount and the both chromium and nickel are compulsory elements to form such corrosive protection film

Regarding the reconciliation of the corrosion rates of metals with respect to both Murban and Das Blend crude oils four types of metals showed their higher corrosion rates in Murban crude oil while other three types of metals were showing their higher corrosion rates in Das Blend crude oil since Das Blend crude oil having higher amounts of organic acids, elemental sulfur and Mercaptans also less amount of salts than the Murban crude oil. Already explained the temperature requirement of both "sulfidation" and "localized corrosion" and it's impossible to expect a significant 
contribution from the sulfur compounds for the results of the current experiment [2]-[24]. By mostly considering the contributions of the impact from the salts and organic acids presence in crude oil there can be reached to some impartial approaches.

- The corrosion process due to the salts is more possible than the corrosion process due to the acids

- Both processes are much likely to happen simultaneously because of the less requirements of the temperature and the reactivity of both previously $\mathrm{FeS}$ and Fe with the organic acids

- There can be expected the higher impact on the metallic corrosion from both of elemental sulfur and Mercaptans at the different high temperature applicable processes in the crude oil refining process such as the pre heaters, crude distillation column, sulfur removing units and the reactors.

The variations of the corrosion rates of metal types with respect to the exposed time period in both Murban and Das Blend crude oils have been graphically shown in the Figure. 4(a) and Figure 4(b).

(a)

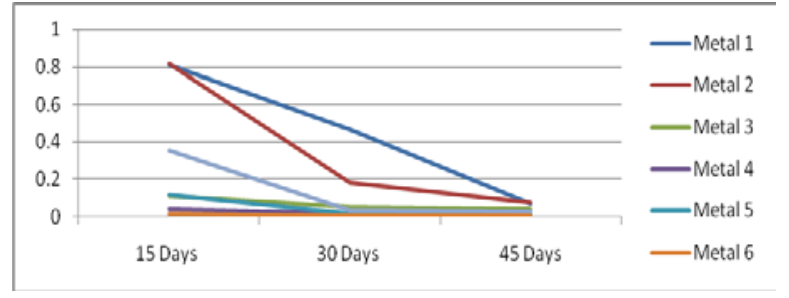

(b)

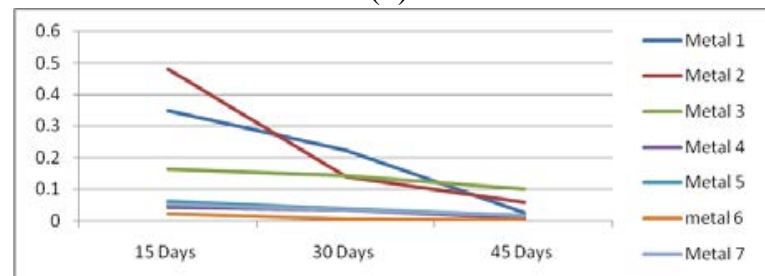

Figure.4. Variations of the corrosion rates of metals with the exposure time period against the (a) Murban and (b) Das Blend crude oils

Basically there were observed the similar variations of the corrosion rates of metal types with the increasing of the exposed time period although found some different lines with different values. By observing the variations of the corrosion rates of metals with the exposure time against the crude oils it can be concluded the validity of the inversely proportional relationship in between the corrosion rate and the exposure time period for any kind of metal and for the crude oils as the corrosive environment as well [10][18].

3.4 Microscopic observations of the corrosion: According to the qualitative analysis of the corrosion compounds on the metal coupons by the optical microscope a few of highlighted observations have been shown in the Fig 5(a) Fig 5(b), Fig 5(c) and Fig 5(d).

(a)
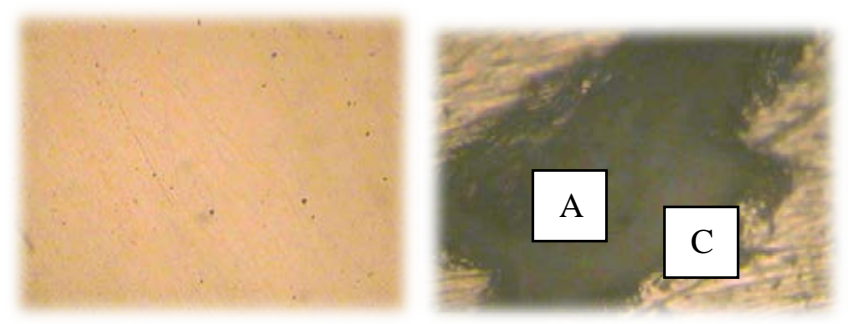

(b)
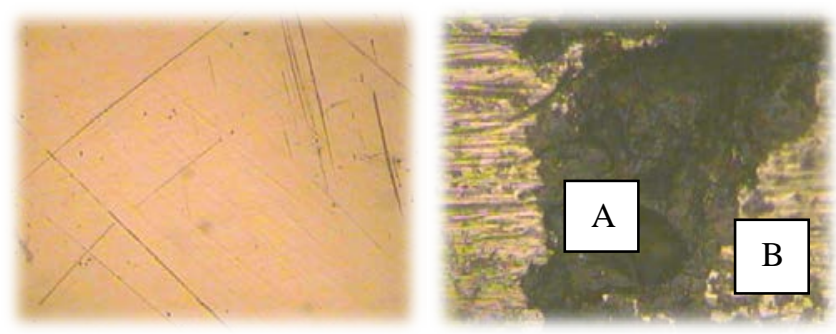

(c)
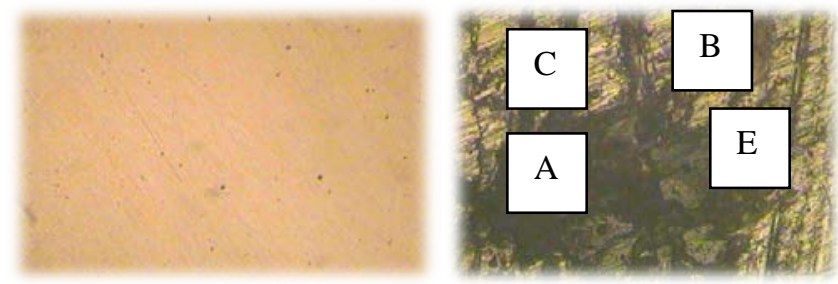

Figure.5. Corroded metal surface of (a) Carbon steel (high) in Das Blend (b) carbon steel (medium) in Das Blend (c) 410MN: 1.7 420- MN: 1.7 (stainless steel) in Murban and (d) Carbon Steel (Mild Steel) in Murban

The identifications were done by using the visible features of the corrosion compounds that have been formed when the metal surfaces were exposing to the crude oils. The special and distinguished observations have been shortlisted in the below.

- A- Black patches with some irregular spread

- B- Rusty color in irregularly distributed

- C- Some cracks with black color

- D- Some cavities with black or metal color

- $\quad$ E- Patches with the color of rusty and black mixed

The references and the observations have been compared with some enough evidences to confirm the formation of such compounds in the Table 6 [1] [4] [5].

Table 6. Appearances of corrosion compounds

\begin{tabular}{|c|c|c|}
\hline Compound & Appearances & Observations \\
\hline FeS & $\begin{array}{c}\text { Black, brownish } \\
\text { black, property of }\end{array}$ & $\begin{array}{c}\text { Observed most of } \\
\text { features in each }\end{array}$ \\
\hline
\end{tabular}




\begin{tabular}{|c|c|c|}
\hline & $\begin{array}{c}\text { powder, pitting, } \\
\text { cracks }\end{array}$ & metal piece. \\
\hline $\mathrm{Fe}_{2} \mathrm{O}_{3}$ & Rusty color & Observed rarely. \\
\hline $\mathrm{CuS}$ & $\begin{array}{c}\text { Dark indigo/ dark } \\
\text { blue }\end{array}$ & Unable to specify. \\
\hline
\end{tabular}

By referring the observations and the theoretical explanations that there can be confirmed the formation of FeS in most of corrosion process in this current experiments as explained under the corrosive compounds in crude oils. In addition some corrosion cracks and pitting corrosion were observed on some stainless steels also found some rusty color compounds rarely apart from FeS [1][3][4][5]. The rusty color compound can be concluded as $\mathrm{Fe}_{2} \mathrm{O}_{3}$ because of the less tendency of the formation of such compound with the effect of composed water in crude oils and dissolved oxygen in crude oils. As an uncertain observation there were observed some black or more closed to dark blue patches on the Monel metal surfaces although it was quite difficult to distinguish from FeS only considering visible appearances as CuS definitely. Therefore, it is possible to suggest some advance compositional analysis to clarify the compound exactly such as the X-ray diffraction for further enhancement of the current research to obtain better results [14][15][20].

3.5 Decay of metals into crude oils: According to analysis of decayed ferrous and copper amounts into crude oils from metals by the atomic absorption spectroscopy (AAS) the obtained results have been interpreted as it is in the Table 7 .

Table 7. The results of the atomic absorption spectroscopic (AAS) analysis of crude oils

\begin{tabular}{|c|c|c|c|}
\hline \multirow{2}{*}{ Metal } & Crude Oil & $\begin{array}{c}\text { Fe } \\
\text { Concentration } \\
\text { /ppm }\end{array}$ & $\begin{array}{c}\text { Cu } \\
\text { Concentration } \\
\text { /ppm }\end{array}$ \\
\hline $\begin{array}{c}\text { Carbon } \\
\text { Steel } \\
\text { (High) }\end{array}$ & Murban & 0.47 & - \\
\cline { 2 - 4 } $\begin{array}{c}\text { Carbon } \\
\text { Steel } \\
\text { (Medium) }\end{array}$ & Das Blend & 1.10 & - \\
\cline { 2 - 4 } & Darban & 0.54 & - \\
\hline $\begin{array}{c}\text { Carbon } \\
\text { Steel } \\
\text { (Mild Steel) }\end{array}$ & Murban & 0.02 & - \\
\cline { 2 - 4 } $\begin{array}{c}410-M N: 1.8 \\
420-\end{array}$ & Das Blend & -0.48 & - \\
\cline { 2 - 4 } $\begin{array}{c}\text { MN:2.8 } \\
\text { (Stainless } \\
\text { Steel) }\end{array}$ & Das Blend & -0.65 & - \\
\hline $\begin{array}{c}410-M N: 1.7 \\
420-M N: 1.7 \\
\text { (Stainless } \\
\text { Steel) }\end{array}$ & Murban & -0.78 & - \\
\cline { 2 - 4 } & Das Blend & -0.79 & - \\
\hline $\begin{array}{c}321-M N: 1.4 \\
\text { 304-MN:1.9 }\end{array}$ & Murban & -0.44 & - \\
\cline { 2 - 4 } & Das Blend & -0.17 & - \\
\hline
\end{tabular}

\begin{tabular}{|c|c|c|c|}
\hline $\begin{array}{c}\text { (Stainless } \\
\text { Steel) }\end{array}$ & & & \\
\hline \multirow{2}{*}{ Monel 400} & Murban & - & 10.47 \\
\cline { 2 - 4 } & Das Blend & - & 9.49 \\
\hline
\end{tabular}

The above results showed the similarity with the obtained results for the distributions of the corrosion rates with respect to both crude oils. Basically these results show the higher decay of ferrous from both carbon steel (high) and carbon steel (medium) into both Murban and Das Blend crude oils and also significant decay of copper from the Monel metal into both Murban and Das Blend crude oils. The special and discrimination observation that there can be seen lack of ferrous decay into any crude oil from carbon steel (mild steel) and any stainless steel also found relatively less corrosion rates from the in both Murban and Das Blend crude oils. After formation of the corrosion compounds on the metal surfaces such newly formed heterogeneous corrosion compounds tend to be removed from the initial metal surface due to repulsive and attractive forces between successive electrons and protons of relevant atoms [1][3][4][5][19][21]. Therefore, it can be explained the decay of metal would be the equitable reason for the invisible weight loss of metal coupons during the corrosion.

3.6 Variations of the initial hardness of metals: According to the analysis of the initial and hardness after formation of the corrosion on the metal surfaces by the Vicker's hardness tester the variations of the initial hardness of metal coupons in both Murban and Das Blend crude oils after 45 days immersion time period have been shown in the Figure. 6(a) and Figure. 6(b).

(a)

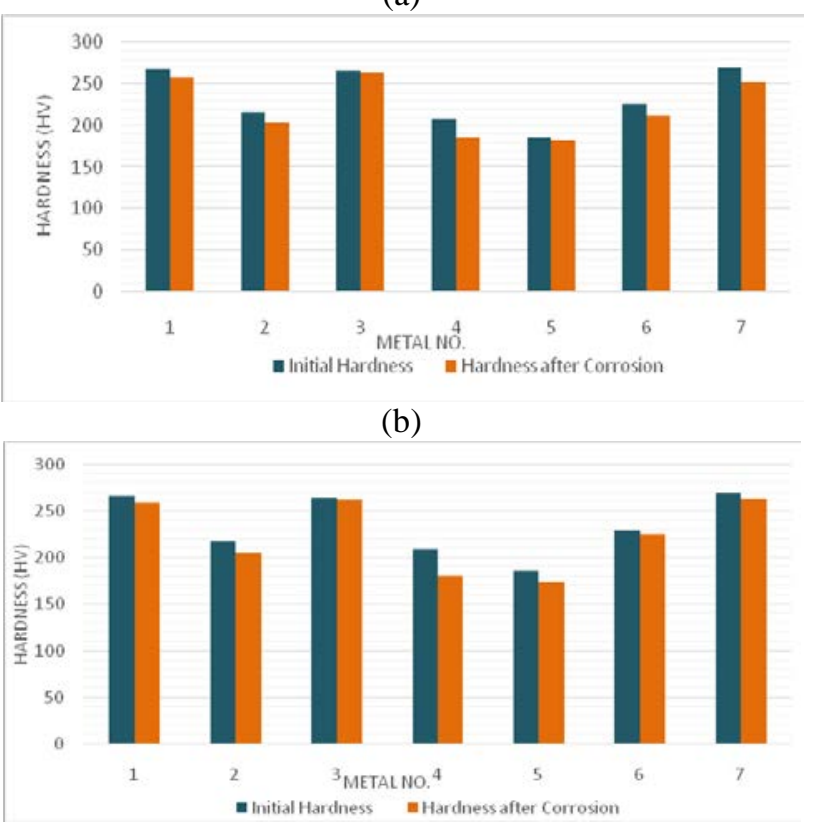

Figure.6. Variations of the initial hardness of metal coupons in (a) Murban and (b) Das Blend crude oils 
The above graphs showed that there can be observed some slight reductions of the initial hardness of each metal coupon after exposed to any type of crude oil either Murban or Das Blend while occurring the corrosion on the metallic surface itself. During the process of the destructions of metals due to the corrosion there may be a tendency of forming an unstable condition on the relevant metal surface with the effects of the attractive and repulsive forces between the successive protons and electrons of the relevant atoms [1][3][5][19][22]. Therefore, the obtained results can be used as a confirmation stage of the formation of the metallic corrosion in the current experiment and the property changes of the metals due to the corrosion forever.

\section{Conclusions}

The least corrosion rates were observed from 321-MN: 1.4 304-MN: 1.9 (Stainless Steel) in both Murban and Das Blend crude oils among other metal types because of the performances of self corrosive protection layer which is created with nickel and chromium. The Das Blend crude oil was richer in sulfur content and the acidity since weaker in salt content than the Murban crude oil. Although there were observed some improper proper progress of elemental sulfur and active sulfur compounds at the room temperatures and also it was observed some higher ascendency from the salts in the metallic corrosion rather than the impact of the organic or naphthenic acids in the metallic corrosion at the room temperatures. In addition there were observed some significant decays of copper and ferrous from some metals which were shown relatively higher corrosion rates in both Murban and Das Blend crude oils also there were observed slight reductions of the initial hardness of most of metal coupons after the formations of the corrosion compounds on the metal surface. Finally there can be concluded the formation of FeS with some corrosion cracks and cavities also recommend a compositional analysis of such corrosion compounds by an advanced method such as X-ray diffraction (XRD), determination of the corrosion rates of metal coupons by using a digital analytical instrument instead of the weight loss method or compare the accuracy of both methods under separate experiments and the investigation of the effect of hydrogen sulfide on the metallic corrosion by well developed methods and instruments forever.

\section{Appendix}

In addition the observations and literature review that there have been distinguished different types of corrosion mechanisms under various chemical processes [1]-[24].

General Corrosion

- Associated with atmospheric corrosion.

- Oxidation and sulfidation in high temperature are the major processes in this type of corrosion.

Pitting Corrosion
- Creation of pits on the surface of metal.

- Pits can be formed within less or lack of general corrosion

\section{Crevice Corrosion}

- Similar to pitting corrosion. Associated with crevices.

- In stainless steel, there can be seen this type of corrosion abundantly.

Intergranular Corrosion

- Corrosion reaction is happened in grain boundaries of the metal.

- Corrosion is happened due to the thermal treatments.

Dealloying

- Removal of one element from and alloy into the environment of corrosive.

\section{Corrosion Fatigue}

- Formation and extension of the cracks due to the overall effect of the stress and corrosive reactions.

Galvanic Corrosion

- Acceleration of the corrosion due to the coupling of the noble trace metal with another metal.

Erosion- Corrosion

- Acceleration of corrosion due to the flowing fluids, solids or gases whiles the formation of cavities and eroding the surface of the metal.

Stress Corrosion Cracking

- Generation and propagation of cracks due to the overall effect of the corrosive environment and the tensile stress.

- The process of cracking tends to be increased with the temperature.

Hydrogen Damage

- Hydrogen induced cracking with the contribution of tensile stress and hydrogen atoms.

\section{Acknowledgement}

The author's special compliment goes to the supervisor, laboratory staff members and technical staff members those who has subscribed on this work to meet the all achievements in beneficially.

\section{References}

1. O.P Khana., Materials Science and Metallurgy, New Delhi, India: Dhanpet Rai and Sons publication, 2009.

2. M.A. Fahim, T.A. Alsahhaf and A. Elkilani, Fundamentals of Petroleum Refining, Amsterdam, The Netherland: Radarweg Press, 2010.

3. W. D. Calister, An Introduction of Materials Science and Engineering, New York: John Wiley \& Sons, Inc, 2003. 
4. M.E. Davis and R.J. Davis, Fundamentals of Chemical Reaction Engineering, $1^{\text {st }}$ Ed. New York: McGraw-Hill, 2003.

5. R. Singh, Introduction to Basic Manufacturing Process and Engineering Workshop, New Delhi, India: New Age International Publication, 2006.

6. W. Bolton, Engineering Materials Technology, $2^{\text {nd }}$ Ed. London, United Kingdom: B. H Newnes Limited, 1994.

7. H. A. Ajimotokan, A. Y. Badmos and E. O. Emmanuel, “Corrosion in Petroleum Pipelines," New York Science Journal, vol.2, no.5, pp. 36-40, 2009.

8. J.G. Speight, The Chemistry and Technology of Petroleum, $3^{\text {rd }}$ Ed. New York: Marcel Dekker, 1999.

9. G. A. Afaf, "Corrosion Treatment of High TAN Crude," PhD. Thesis, University of Khartoum, Khartoum, Sudan, 2007.

10. G. C. Okpokwasili and K. O. Oparaodu, "Comparison of Percentage Weight Loss and Corrosion Rate Trends in Different Metal Coupons from two Soil Environments," International Journal of Environmental Bioremediation \& Biodegradation, vol.2, no.5, pp. 243-249, 2014.

11. A.D. Usman and L.N. Okoro, "Mild Steel Corrosion in Different Oil Types," International Journal of Scientific Research and Innovative Technology, vol.2, no.2, pp. 913, Feb., 2015.

12. I.M. Ahmed, M.M. Elnour and M.T. Ibrahim, "Study the Effects of Naphthenic Acid in Crude Oil Equipment Corrosion," Journal of Applied and Industrial Sciences, vol.2, no.6, pp. 255-260, Dec., 2014.

13. G.W. Luther and D. Rickard, "Chemistry of Iron Sulfides,” Chemical Reviews, vol.107, no.2, pp. 514-562, 2007.

Biographical notes
14. H. Fang, S. Nesic and D. Young, "Corrosion of Mild Steel in the Presence of Elemental Sulfur," in International Corrosion Conf. and Expo, 2008.

15. G. M. Bota, S. Nesic, D. Qu and H.A. Wolf, "Naphthenic Acid Corrosion of Mild Steel in the Presence of Sulfide Scales Formed in Crude Oil Fractions at High Temperature," in International Corrosion Conf. and Ехро, 2010.

16. M. A. Maleque and M. S. Salit, Materials Selection and Design, Springer Briefs in Material, 2013.

17. C. Drummond, and J. Israelchvili, "Fundamental studies of crude oil surface water interaction and its relationship to reservoir wettability,” Journal of Petroleum Science \& Engineering, Vol. 45, pp. 61-81, 2003.

18. K. D. Efird, Corrosion tests and standards metal, Chap. 36, pp. 351-363.

19. A. Groysman, Corrosion for everybody, Dordrecht, The Netherland: Springer 2010, p. 132-150.

20. N. J. Laycock, J. Stewart and R. C. Newman, Corrosion Science, 1997.

21. J. Mankowski and Z. SzklarskaSmialowska, Corrosion Science, sec. 15, 1975.

22. M. Muller, "Theoretical Considerations on Corrosion Fatigue Crack Initiation,” Metallurgical Transactions, Vol. 13, pp. 649-655, 1982.

23. W.F. Smith, and J. Hashemi, Foundations of Material Science and Engineering, $4^{\text {th }}$ Ed. New York: McGrawHill, 2006.

24. N. S. Hassan, “The Effect of Different Operating Parameters on the Corrosion Rate of Carbon Steel in Petroleum Fractions," Engineering and Technology Journal, Vol. 31A, pp. 1182- 1193, 2013.

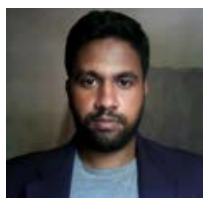

Suresh Aluvihara has received his B.Sc. degree from Uva Wellassa University in Mineral Resources and Technology and currently he is reading for his M.Sc. degree in Environmental and Pollution Control Engineering. He is a postgraduate scholar at the Department of Chemical and Process Engineering, Faculty of Engineering, University of Peradeniya, Peradeniya, Sri Lanka. His research interest includes Chemical and Petroleum Engineering, Mineral Processing, Mineral Science and Water Engineering. 